\title{
ON SOME MEANS DERIVED FROM THE SCHWAB-BORCHARDT MEAN
}

\author{
EDWARD NEUMAN
}

\begin{abstract}
Bivariate means defined as the Schwab-Borchardt mean of two bivariate means are investigated. Explicit formulas for those means are obtained. It is demonstrated that they interpolate inequalities connecting the well known bivariate means. Optimal bounds for the means under discussion are also obtained. The bounding quantities are convex combinations of the generating means.
\end{abstract}

Mathematics subject classification (2010): 26E60, 26D05, $26 \mathrm{D} 07$.

Keywords and phrases: Schwab-Borchardt mean, Seiffert means, logarithmic mean, convex combinations, total positivity, inequalities.

\section{REFERENCES}

[1] H. Alzer, S.-L. QIU, Monotonicity theorems and inequalities for complete elliptic integrals, J. Comput. Appl. Math. 172 (2004), 289-312.

[2] J. M. Borwein, P. B. Borwein, Pi and the AGM: A Study in Analytic Number Theory and Computational Complexity, John Wiley and Sons, New York, 1987.

[3] B. C. CARLSON, Algorithms involving arithmetic and geometric means, Amer. Math. Monthly 78 (1971), 496-505.

[4] B. C. CARlson, J. L. Gustafson, Total positivity of mean values and hypergeometric functions, SIAM J. Math. Anal. 14 (1983), 389-395.

[5] Y.-M. CHU, S.-W. Hou, Sharp bounds for Seiffert mean in terms of contra-harmonic mean, Abstr. Appl. Anal. 2012 (2012), Article ID 425175.

[6] Y.-M. CHU, S.-W. Hou, Z.-H. SHEN, Sharp bounds for Seiffert mean in terms of root mean square, J. Inequal. Appl. 2012, 11 (2012), 15 pages.

[7] Y.-M. ChU AND B.-Y. LONG, Bounds of the Neuman-Sándor mean using power and identric means, Abstr. Appl. Anal. 2013, Article ID 832591, 6 pages.

[8] Y.-M. CHU, B.-Y. Long, W.-M. Gong AND Y.-Q. Song, Sharp bounds for Seiffert and NeumanSándor means in terms of generalized logarithmic means, J. Inequal. Appl. 2013, 10 (2013), 13 pages.

[9] Y.-M. ChU, Y.-F. QIU, M.-K. WANG, G.-D. WANG, The optimal convex combination bounds of arithmetic and harmonic means for the Seiffert mean, J. Inequal. Appl. 2010 (2010), Article ID 436457.

[10] Y.-M. ChU, M.-K. WANG, W.-M. Gong, Two sharp double inequalities for Seiffert mean, J. Inequal. Appl. 2011, 44 (2011), 7 pages.

[11] Y.-M. ChU, M.-K. WANG, Z.-K. WANG, A best possible double inequality between Seiffert and harmonic means, J. Inequal. Appl. 2011, 44 (2011), 7 pages.

[12] Y.-M. ChU, C. Zong, G.-D. WANG, Optimal convex combination bounds of Seiffert and geometric means for the arithmetic mean, J. Math. Inequal. 5 (2011), 429-434.

[13] S.-Q. GAO, H.-Y. GAO, W.-Y. SHI, Optimal convex combination bounds of the centroidal and harmonic means for the Seiffert mean, Int. J. Pure Appl. Math. 70 (2011), 701-709.

[14] Z.-Y. HE, W.-M. QIAN, Y.-L. JiAnG, Y.-Q. Song AND Y.-M. ChU, Bounds for the combination of Neuman-Sándor, arithmetic, and second Seiffert means in terms of contraharmonic mean, Abstr. Appl. Anal., 2013, Article ID 903982, 5 pages.

[15] R. Kleń, M. Visuri, M. VuORInen, On Jordan type inequalities for hyperbolic functions, J. Inequal. Appl., vol. 2010, Article ID 362548, 14 pages. 
[16] Y.-M. LI, B.-Y. Long, Y.-M. CHU, Sharp bounds for the Neuman-Sándor mean in terms of generalized logarithmic mean, J. Math. Inequal. 4, 4 (2012), 567-577.

[17] H. LiU, X.-J. Meng, The optimal convex combination bounds for Seiffert's mean, J. Inequal. Appl. 2011 (2011), Article ID 686834.

[18] D. S. Mitrinović, Analytic Inequalities, Springer-Verlag, Berlin, 1970.

[19] E. NeumAN, Inequalities for the Schwab-Borchardt mean and their applications, J. Math. Inequal. 5, 4 (2011), 601-609.

[20] E. Neuman, A note on a certain bivariate mean, J. Math. Inequal. 6, 4 (2012), 637-643.

[21] E. Neuman, Refinements and generalizations of certain inequalities involving trigonometric and hyperbolic functions, Adv. Inequal. Appl. 1, 1 (2012), 1-11.

[22] E. Neuman, Inequalities involving Jacobian elliptic, trigonometric and hyperbolic functions, J. Inequal. Spec. Funct. 3, 2 (2012), 16-21.

[23] E. Neuman, A one-parameter family of bivariate means, J. Math. Inequal., 7, 3 (2013), 399-412.

[24] E. Neuman, Sharp inequalities involving Neuman-Sándor and logarithmic means, J. Math. Inequal., 7, 3 (2013), 413-419.

[25] E. NEUMAN, Inequalities involving certain bivariate means II, J. Inequal. Spec. Funct., in press.

[26] E. Neuman, J. SÁndor, On the Schwab-Borchardt mean, Math. Pannon. 14, 2 (2003), 253-266.

[27] E. Neuman, J. SÁndor, On the Schwab-Borchardt mean II, Math. Pannon. 17, 1 (2006), 49-59.

[28] W.-M. QIAN AND Y.-M. CHU, On certain inequalities for Neuman-Sándor mean, Abstr. Appl. Anal., 2013, Article ID 790783, 6 pages.

[29] H.-J. SEIFFERT, Problem 887, Nieuw. Arch. Wisk. 11 (1993), 176.

[30] H.-J. SEIFFERT, Aufgabe 16, Würzel 29 (1995), 87.

[31] Y.-Q. Song, W.-M. QIAN, Y.-L. JIANG AND Y.-M. ChU, Optimal lower generalized logarithmic mean bound for the Seiffert mean, J. Appl. Math., 2013, Article ID 273653, 5 pages.

[32] M.-K. WANG, Y.-M. ChU, B.-Y. LiU, Sharp inequalities for the Neuman-Sándor mean in terms of arithmetic and contra-harmonic means, preperint, arXiv: 1209.5825 vol 1 [math CA] 26 Sept. 2012.

[33] A. WitKows KI, Interpolations of Schwab-Borchardt means, Math. Inequal. Appl. 16, 1 (2013), 193206.

[34] T.-H. Zhao, Y.-M. Chu, Y.-L. Jiang AND Y.-M. Li, Best possible bounds for Neuman-Sándor mean by identric, quadratic and contraharmonic means, Abstr. Appl. Anal., 2013, Article ID 348326, 12 pages.

[35] T.-H. ZhaO, Y.-M. ChU, B.-Y. LiU, Optimal bounds for the Neuman-Sándor mean in terms of the convex combinations of harmonic, geometric, quadratic and contra-harmonic means, Abstract Appl. Anal. Volume 2012, Article ID 302635, 9 pages. 